\title{
Mapping the distribution of invasive shrub Austroeupatorium inulifolium (Kunth) R. M. King \& H. Rob: A case study from Sri Lanka
}

\author{
I. P. K. Piyasinghe ${ }^{1,2}$, J. Gunatilake ${ }^{3}$ and H. M. S. P. Madawala ${ }^{1}$ \\ ${ }^{1}$ Department of Botany, Faculty of Science, University of Peradeniya, Peradeniya, Sri Lanka \\ ${ }^{2}$ Postgraduate Institute of Science, Peradeniya, Peradeniya, Sri Lanka \\ ${ }^{3}$ Department of Geology, Faculty of Science, University of Peradeniya, Peradeniya, Sri Lanka
}

Received:18/11/2017; Accepted:11/02/2018

\begin{abstract}
A light loving invasive shrub, Austroeupatorium inulifolium has been spreading many land use types in the Knuckles Forest Reserve (KFR) in Sri Lanka, including man-made grasslands. In developing countries, there are limitations of using novel technologies to quantify and track the distribution of invasive species due to high costs and lack of facilities. This is a setback for their early detection and to introduce effective control measures. This pilot study attempted to map the distribution of $A$. inulifolium in man-made grasslands in KFR using high spatial multispectral images. Unsupervised, supervised and knowledge-based classifications were performed to quantify the spatial distribution of $A$. inulifolium in ERDAS Imagine. The results generated comparable results of the extent of area under $A$. inulifolium by using the unsupervised (108 ha), supervised ( $94 \mathrm{ha}$ ) and knowledge-based classifications (93 ha). They were 18, 15 and $15 \%$ from the total area selected for the study (622 - 646 ha), respectively. The results indicated the suitability of high spatial multispectral imageries in quantifying the spatial distribution of A. inulifolium. Further studies are recommended to investigate long-term changes in invasive plant population using multi temporal satellite data.
\end{abstract}

Keywords: Spatial distribution, Austroeupatorium inulifolium, Worldview-2, invasive shrub, Sri Lanka.

\section{INTRODUCTION}

Mapping the distribution of problematic plant species is critical in order to monitor their future spread and to introduce effective management strategies. Remote Sensing (RS) together with Geographic Information System (GIS) has been successfully used in spatial mapping of plant populations to predict and/or model their future distributions (McCormick, 1999; Haltuch et al., 2000; Stow et al., 2000). Prior to the attention on single species in concern, scientists have been using RS and GIS to detect major ecosystem-level changes over time due to natural and anthropogenic disturbances (Wang, 2008). The canopy species can be easily detected by their unique phenological events, biochemical properties and structural features (McCormick, 1999, Haltuch et al., 2000; Underwood and Ustin, 2007). Müllerováa et al., (2017) emphasize the importance of field data to increase the accuracy of pixeland object-based classifications for mapping herbaceous invasive plants such as giant hogweed (Heracleum mantegazzianum) and knotweeds (Fallopia japonica, F. sachalinensis and their hybrid $F$. $\times$ bohemica). Previous studies stated that RS together with field data can provide a successful combination in mapping invasive plants in the understory (Jones et al., 2011; Somodi et al., 2012; Delalieux et al., 2012; Shouse et al., 2013; Müllerováa et al., 2017).

When selecting satellite imagery for mapping the distribution of an invasive species, the prospects of the final outcome and sensor characteristics are need to be considered. The changes associated with reflection and absorption patterns are used to identify individual species with high accuracies and also allow mapping plants in low densities (Underwood and Ustin, 2007). Previous studies successfully used WorldView-2 to map the distribution of invasive herbs and shrubs (Dlamini, 2006; Sankey et al., 2012; Sankey et al., 2014; Lin et al., 2015; Peerbhay et al., 2015; Immitzer et al., 2016). Dlamini (2006) successfully detected two shrubs, Lantana camara and Chromaleana odorata in ranches of flat terrain in central Swaziland, southern Africa with Worldview-2 and noted its efficacy and applicability. Sankey et al., (2014) effectively detected small populations of Brassica tournefortii, an invasive forb in Mojave and Sonoran Deserts in the southwestern USA using WorldView-2, following an object-oriented image analysis approach. The mapping of an invasive shrub, Hakea sericea showed user and producer accuracies greater than 93\% using WorldView-2 (Alvarez-Taboada et al., 2017). Peerbhay et al., (2015) also demonstrated the capability and effectiveness of unsupervised classification in detecting and mapping invasive shrub, Solanum mauritianum distributed along forest margins, open grasslands in Sappi Hodgesons Forest Plantation in South Africa using WorldView-2. A pixel-based image analysis carried out in Canada to map the distribution of two small shrubs, Himalayan blackberry (Rubus armeniacus) and English ivy (Hedera helix) showed some promising results with detection accuracies of 80 and 76\%, respectively (Chance et al., 2016). Another success story was recorded from the north-west Pilbara region in Australia with Prosopis sp. using WorldView-2 (Robinson et al., 2016), highlighting its universal applicability in detecting and mapping the distribution of plants. Müllerováa et al., (2013) also emphasized the use of 
$\mathrm{RS}$ as a tool in monitoring long-term dynamics of invasive herb, Heracleum mantegazzianum.

Asutroeupatorium inulifolium, a known invasive species in the tropics, has been steadily invading different landuse types in the KFR in Sri Lanka including degraded Cymbopogon nardus-dominated grasslands, natural grasslands, roadsides, Pinus and Eucalyptus plantations. A. inulifolium appears to take over its invasive nature since early 2000s, silently invading many landuse types. Being a sun-loving shrub, A. inulifolium rarely found under the canopy of the lower montane forests at KFR. The anthropogenic grasslands dominated by $C$. nardus seem to provide the most suitable micro-climatic conditions for $A$. inulifolium, thus making them the most vulnerable landuse types for its invasion. Precise distribution maps of invasive species can be an important source of information for forest officers, researchers and policy makers to monitor their further spread and also to implement effective management measures. Therefore, this pilot study aimed at mapping the spatial distribution of $A$. inulifolium in a selected area in KFR using high spatial resolution images, Worldview-2.

\section{MATERIALS AND METHODS}

\section{Test Species}

Austroeupatorium inulifolium (Kunth) R.M. King \& H. Rob. (Asteraceae), a native of Tropical South America, was later introduced to Sumatra and Java (Dasanayake, 19941995). It was introduced to Sri Lanka during the Second World War II (McFadyen, 2003). The shrub grows up to 1 - $5 \mathrm{~m}$ in height with a conspicuous creamy-white coloured inflorescence. Leaves are opposite, deltoid-ovate, petiolate and gradually acuminate at the apex. Margin is shallowly and regularly serrate glandular, pubescent on both surfaces. Flowering occurs mainly in August. Fruit is an achene (Dasanayake, 1994-1995). A. inulifolium show high coppicing ability and therefore some mature plants may contain 20 or more stems of varying sizes from a single rootstock (McFadyen, 2003).
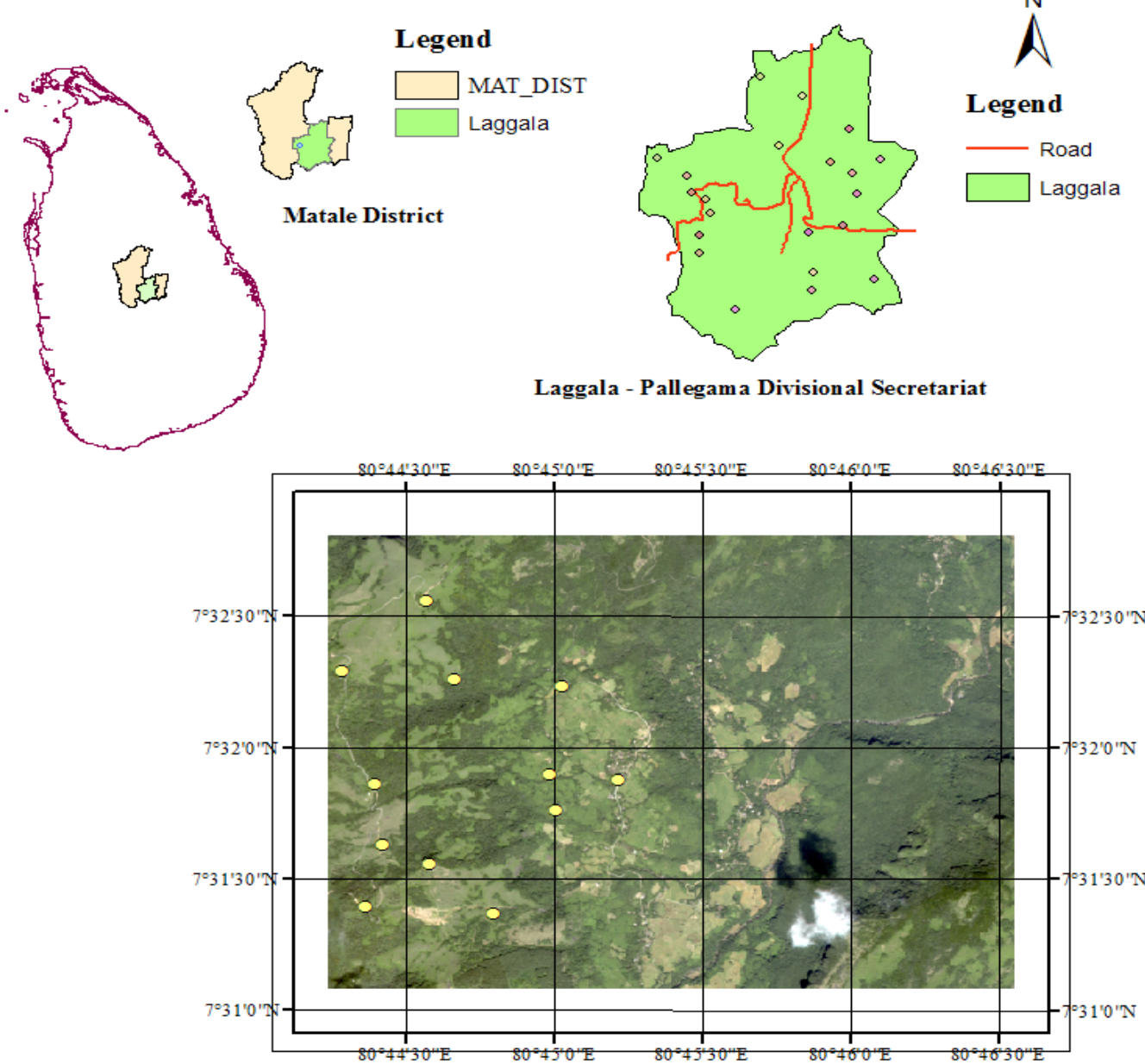

$3,006,000 \quad 12,000 \quad 18,000 \quad 24,000$

Study Area

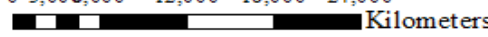

Figure 1: The map showing the selected study site in the Knuckles Forest Reserve in Sri Lanka. The sampling locations are indicated in yellow coloured circles. 


\section{Study area}

The study area covers an approximately 600 ha in KFR with different landuse types including forests (lower montane forests), Pinus plantation, C. nardus-dominated grasslands etc. The selected study area was fallen between North-West Latitude $=7.51$; South-East Longitude $=80.78$ (Figure 1) .

\section{Pre-processing of satellite images}

Image processing was carried out with ERDAS Imagine 2014, while some specific GIS operations were carried out using ArcMap 10.3. Global Positioning System (GPS) locations were collected using a GPS receiver (TRIMBLE Geo XT and Magellan meridian gold) during November, 2014 to April, 2015 to verify the accuracy. A Spectrometer (Spectrometer specifications: Sensor type: - Hamamatsu S 390X (MMS), Sensor size: 256, Spectral Range: 306 - $1129 \mathrm{~nm}$ ) was used to measure the spectral reflectance values of $A$. inulifolium (Figure 3 ).

The WorldView-2 image with low cloud cover was acquired from the Digital Globe on 12 ${ }^{\text {th }}$ February, 2014 (http:/www.digitalglobe.com). The WorldView-2 has both panchromatic and multispectral imageries. Sensor resolution for Panchromatic: $0.46 \mathrm{~m}$ Ground Sample Distance (GSD) at Nadir and for Multispectral: 1.84 meters Latitude $=7.55$; North-West Longitude $=80.72$; South-East

GSD at Nadir (https:/www.satimagingcorp.com/satellitesensors/worldview-2). The image acquired was already orthorectified and geometrically corrected to WGS84 UTM zone 44 projection system. Later, the WorldView-2 multispectral imagery was layer analyzed using ERDAS Imagine

\section{Satellite image classifications}

Three different classification methods were performed viz., unsupervised, supervised (Long, 2014), and knowledge-based classification (Frick et al., 2005). In the unsupervised technique, Iterative Self-Organizing Data Analysis Technique (ISODATA) algorithm was used. The WorldView-2 multispectral imagery ( 8 bands) was classified for 20 clusters by ISODATA algorithm. Using field information, the classified clusters were correlated and three landuse types were identified viz., forest, $C$. nardus-dominated grasslands and A. inulifolium invaded grasslands. Other landuse types such as water, abandoned lands and degraded lands (visible soil layers) were also identified by field information. The classes that obtained were relatively approximate. After the classification was done, classes were overlaid or recoded to test the accuracy of the classification. Finally, the distribution map was illustrated using ERDAS.

In the supervised classification, pixels were classified

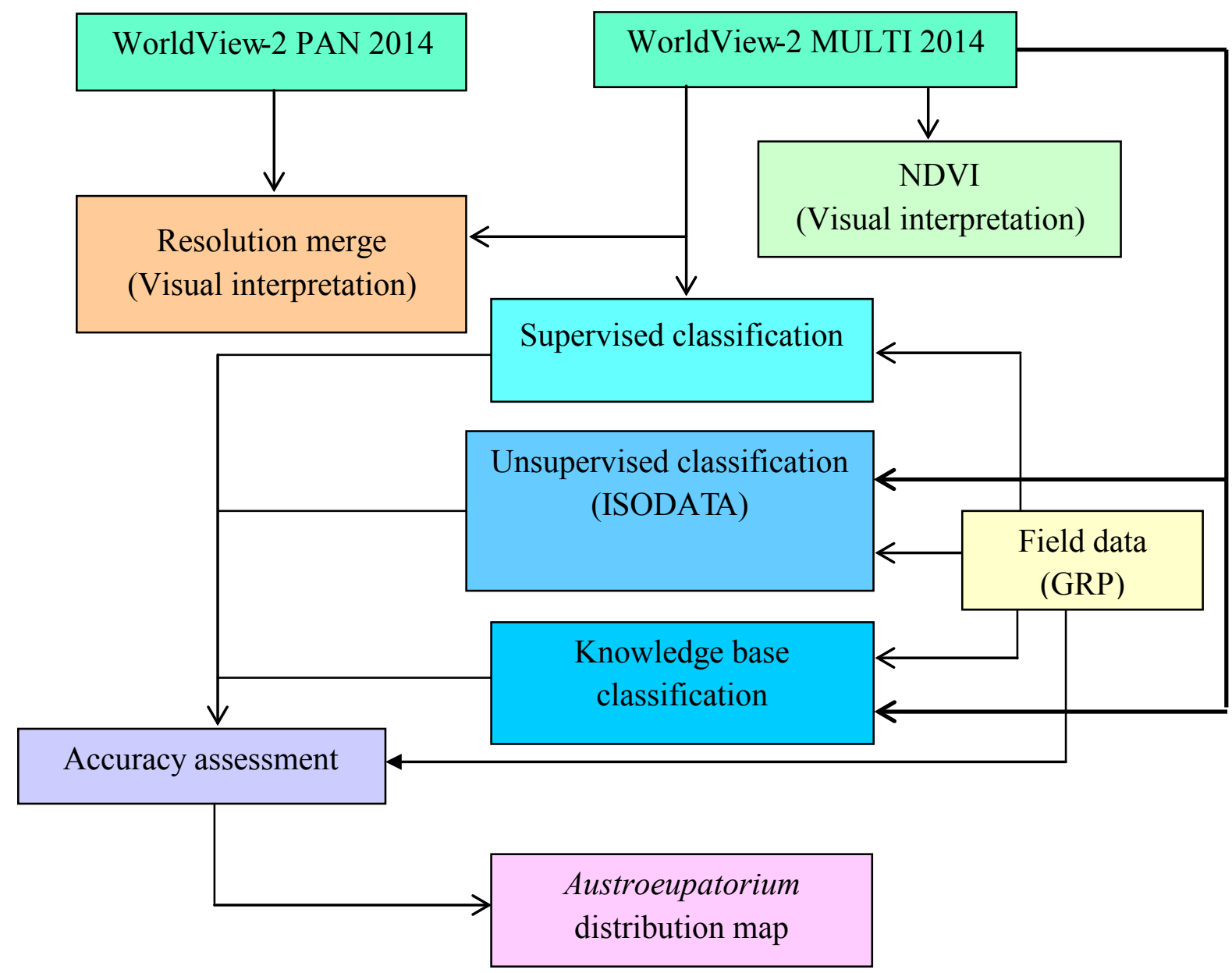

Figure 2: Flow chart depicting the stepwise executions carried out in three different classifications (unsupervised, supervised and knowledge-based) used in the study for preparing spatial distribution maps of A. inulifolium in the selected study area in the Knuckles Forest Reserve, Sri Lanka. (GRP: Ground Reference Points) 
by setting priorities to identified classes using Maximum likelihood algorithms. The "Area of Interest" (AOI) tool was used to collect spectral signatures for landuse types such as forest, C. nardus-dominated grasslands and A. inulifolium invaded grasslands. In addition, water, abandoned lands and degraded lands were also identified. The supervised classification was performed using those recorded spectral signature file. The classified image was visually inspected for accuracy. Specific land cover classes were developed through repeated supervised classifications. An accuracy assessment was performed at the end of the classification.

In knowledge-based classification, the Principal Component Analysis (PCA) was performed for the multispectral image of the WorldView-2 and unique features were analyzed for the components. Number of components desired was set to 8 as it has 8 bands. 'Difference Vegetation Index' (DVI) $[D V I=N I R-R E D]$ was generated for the above PCA image as given by Graham (2016). Once selected the best bands for DVI, different bands were tested for NIR and RED and preview was checked for different land cover classes while the main focus was given to recognize $A$. inulfolium invaded areas. Band 8 was selected for NIR and band 1 was selected for RED as the best for this classification. The textural differences were recognized as forest, grasslands, disturbed and cultivated lands. After performing DVI using NIR-8 and RED-1, A. inulifolium invaded areas were recognized by the histogram of DVI, and was hypothesized that -1320 areas (black colour regions) represented by $A$. inulifolium invaded areas (Graham, 2016). Next, a dendogram was generated using Knowledge Engineer in ERDAS imagine (Graham, 2016). The final classification was executed to isolate $A$. inulifolium pixels. As we gave dark pink to the new hypothesis, dark pink colour regions were detected in the product. Accuracy assessment was done comparing pixels in the classified image file and the class values for the corresponding reference pixels. Reference pixels (points on the classified image) were randomly selected. The stepwise methodology carried out during the three classifications was given in the following flow chart for clarity (Figure 2).

\section{RESULTS AND DISCUSSION}

\section{Spectral signature of Austroeupatorium}

The recorded reflectance values (taken randomly from A. inulifolium plants from different locations within the study area) were graphically presented in the figure 3 . The spectral reflectance plays a key role in discriminating $A$. inulifolium from co-occuring $C$. nardus in this study. The spectral features specified as a finger print in recognition of invasive plants in RS studies (Underwood et al., 2007; He et al., 2011).

\section{Distribution of Austroeupatorium}

In supervised and unsupervised maps, A. inulifolium invaded areas are shown in dark pink colour while $C$. nardus-dominated grasslands in yellow (Figures $4 \mathrm{a}$ and $\mathrm{b}$ ). According to the maps, $A$. inulifolium invasion was more or less confined to forest-grassland edges with the trend of spreading towards $C$. nardus-dominated grasslands, often demarcated by lower montane forest patches. An accuracy assessment was carried using overall accuracy and kappa coefficient based on error matrices to compare the classified image with the reference data (Amiri and Hosseini, 2012). According to the error matrix, the producer and user accuracies of the supervised classification were $100 \%$. The Overall classification accuracy was also $100 \%$ with Overall Kappa $\left(\mathrm{K}^{\wedge}\right)$ Statistics at 1.000. Producers and user accuracies of each classified class (Forests, A. inulifolium invaded areas, $C$. nardus-dominated grasslands etc.) showed a $100 \%$ accuracy.

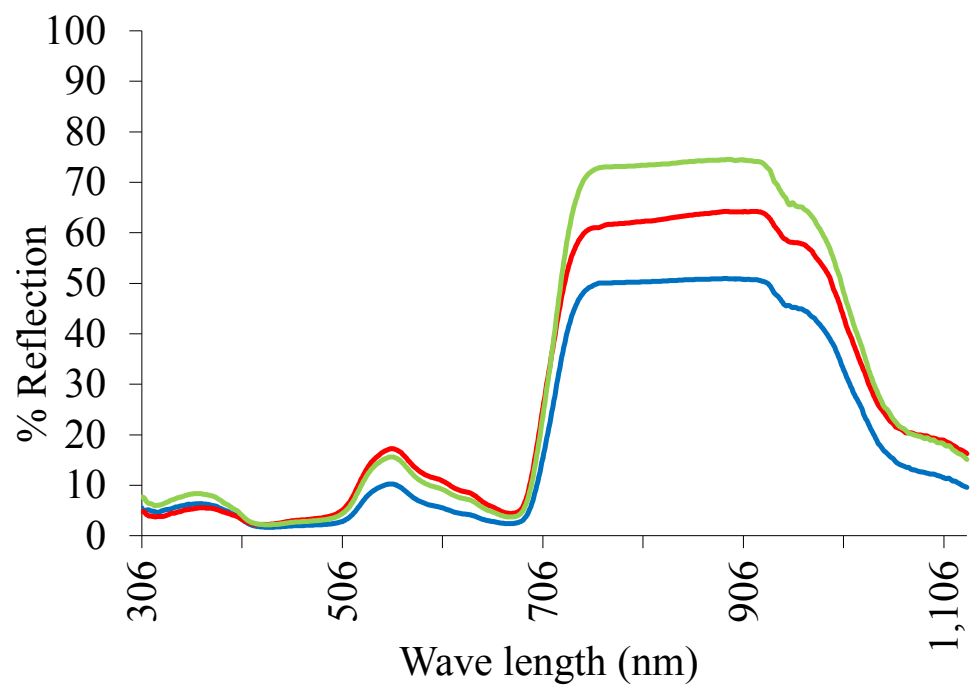

Figure 3: The percentage spectral reflectance [(reflectance of test plant)/(reflectance of white light)] $\times 100)$ of Austroeupatorium inulifolium leaves. Each line of different colours represents measurements taken from separate plants. 
Table 1: The area covered by different landuse classes in the selected study area according to the images produced by unsupervised (ISODATA clustering), supervised (Maximum likelihood algorithm) and knowledge-based classifications.

\begin{tabular}{lcccccc}
\hline \multirow{2}{*}{ Landuse class } & \multicolumn{2}{c}{$\begin{array}{c}\text { Unsupervised } \\
\text { Classification }\end{array}$} & \multicolumn{2}{c}{$\begin{array}{c}\text { Supervised } \\
\text { Classification }\end{array}$} & \multicolumn{2}{c}{$\begin{array}{c}\text { Knowledge-based } \\
\text { Classification }\end{array}$} \\
\cline { 2 - 7 } & Area (ha) & $\mathbf{\%}$ & Area (ha) & \% & Area (ha) & \% \\
\hline Forest & 353.8 & 56.9 & 391 & 62.8 & - & - \\
Grasslands & 85.5 & 13.8 & 98.3 & 15.9 & - & - \\
A. inulifolium invaded area & $\mathbf{1 0 8 . 8}$ & $\mathbf{1 7 . 5}$ & $\mathbf{9 3 . 7}$ & $\mathbf{1 5 . 0}$ & $\mathbf{9 2 . 2}$ & $\mathbf{1 5}$ \\
Abandoned and cultivated land & 58.4 & 9.4 & 37.6 & 6.0 & - & - \\
Water & 15.1 & 2.4 & 2 & 0.32 & - & - \\
\hline Total & 623 & 100 & 623 & 100 & 623 & 100 \\
\hline
\end{tabular}

According to the unsupervised classification, the total extent of the study area selected was 623 ha (by subsetting the selected study area from the originaly classified image), of which $A$. inulifolium invaded area was approximately 109 ha $(18 \%)$ (Table 1). In the supervised classification, the A. inulifolium invaded area was 96.5 ha (15\%), while the knowledge-based classification demarcated an area of 93.2 ha (15\%) (Figure 5, Table 1). The use of GIS and RS techniques in mapping the distribution of plant species has been explored previously, with varying levels of success. The present study observed a comparable area under $A$. inulifolium invasion (15-18\% from the total study area) from all three classification methods. Most applications of $\mathrm{RS}$ in mapping plant species are mainly rely on spatial and spectral patterns. The results of the present study further confirmed the potential use of high resolution satellite imagery to create highly accurate and detailed maps of invasive shrubs such as $A$. inulifolium.

From the three methods used in the study, the unsupervised classification is a fully computer automated method while the supervised and knowledge-based classifications are not fully computer automated methods (Repaka et al., 2004; Müllerováa et al., 2013; Xu, 2014), where the selection of spectral characters or training samples need to be carried out with the help of field-based knowledge. A thorough knowledge on the study area is critical in these classification methods. In supervised classification, well-defined training areas and pure signatures are essential for accurate results (Repaka et al., 2004; Frick et al., 2005). Furthermore, both supervised and unsupervised tools are pixel-based classifications, conversely, in knowledge classifier tool, the decision rules are applied to the base maps to identify vegetation that are not able to be detected based on the pixel-based classification (Xu, 2014).

\section{Comparison of image classifications}

All three generated maps indicated that A. inulifolium stands are mainly confined to forest-grassland edges and spread towards the man-made grasslands. According to the unsupervised classification, A. inulifolium spread was about $18 \%$ of the study area, while grasslands encompassed $14 \%$. Supervied classification too quantified the area under A. inulifolium as $15 \%$, with almost similar results in the knowledge-based classification as well. In favour, previous studies too showed some promising results where the use of spectral features followed by supervised classification with the help of high spatial resolution imagery (Ustin et al., 2002; Gil et al., 2013; Becker et al., 2013). Early studies highlighted the importance of unsupervised classification including ISODATA clustering for mapping invasive plants successfully (Frazier and Wang, 2011; Müllerováa et al., 2013). However, in this study, all three classifiers produced somewhat comparable outcomes. Based on these results, any of the three tested classfiers can be recommended for detecting and monitoring spread of A. inulifolium with the use of high resolution imageries. Rocchini et al. (2015) indicate that generating a distribution model for invasive species with environmental parameters may give more accurate estimates for potential invasion. Therefore, generating a distribution model for $A$. inulifolium with environmental data (geology, rainfall, temperature and wind) is also be recommended as a future study. Furthermore, sequential satellite images may produce more accurate estimates for potential invasion.

\section{Discrimination and detection limits}

A. inulifolium bear rather distinct creamy-white inflorescences, composed of buds and flowers with different maturity stages, hence may not spectrally homogeneous. High spectral variability within entities could reduce the accuracy of pixel-based classification, known as H-resolution problem and salt-and-pepper effect (Yu et al., 2006; Chen et al., 2012). Therefore, the time of the image acquisition can be highly synchronized with its phenological events (Huang and Asner, 2009; Somodi et al., 2012) and seasonal variations (Morisette et al., 2009). Mapping the distribution of invasive plant species has shown promising results with few exceptions (Underwood et al., 2006). The high costs of satellite imageries, software and hardware can be considered as major barriers in lessdeveloped countries (Turner et al., 2003). In addition, a high technical proficiency is needed for processing hyperspectral images. Even though RS could provide efficient and accurate maps to detect the distribution of plants, the classifying and validating images using in situ field measurements is a necessity (Underwood and Ustin, 2007). Though RS is considered as fast and efficient, the 

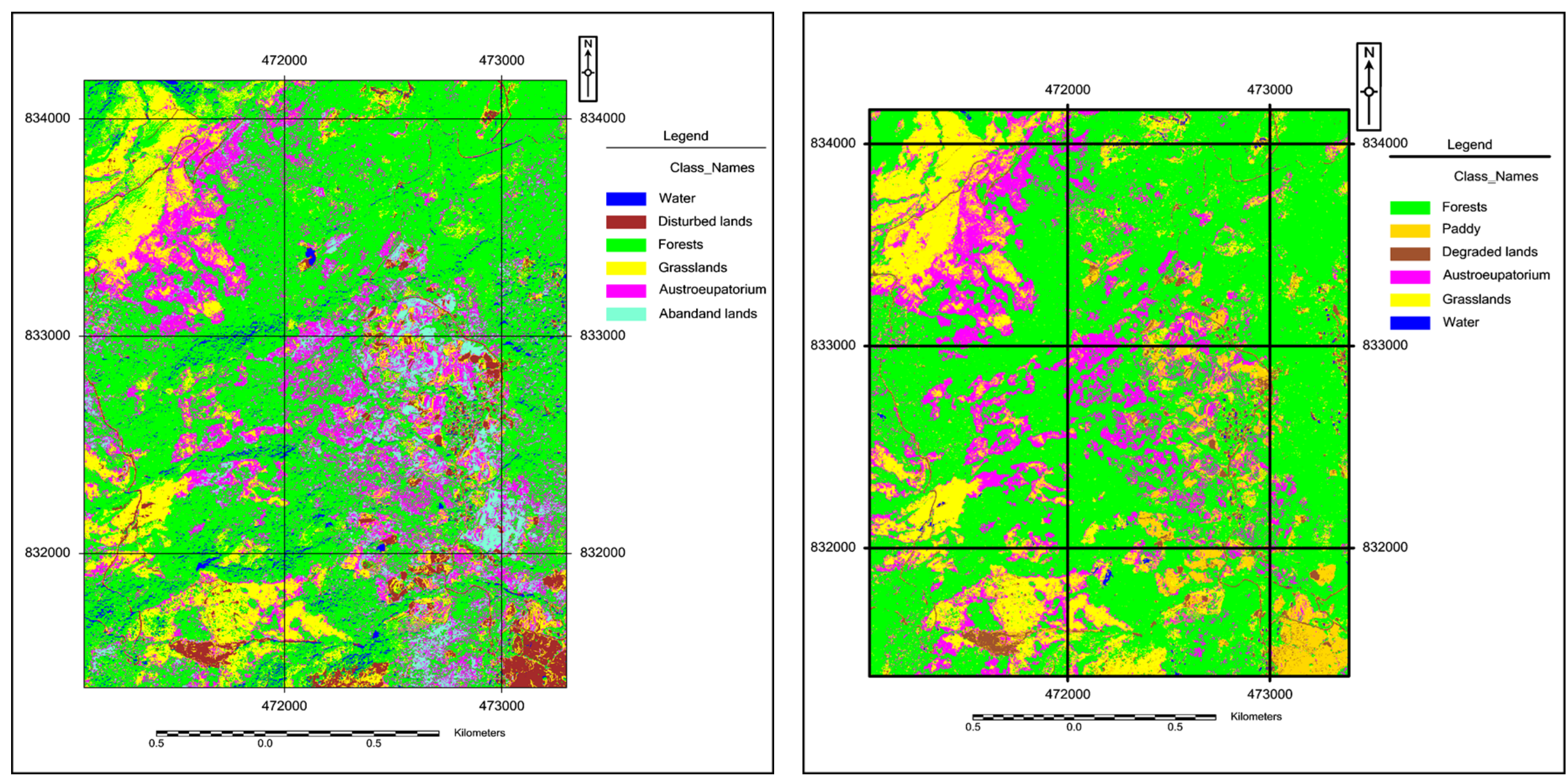

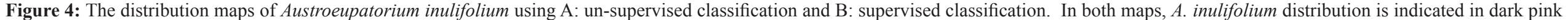
colour. 


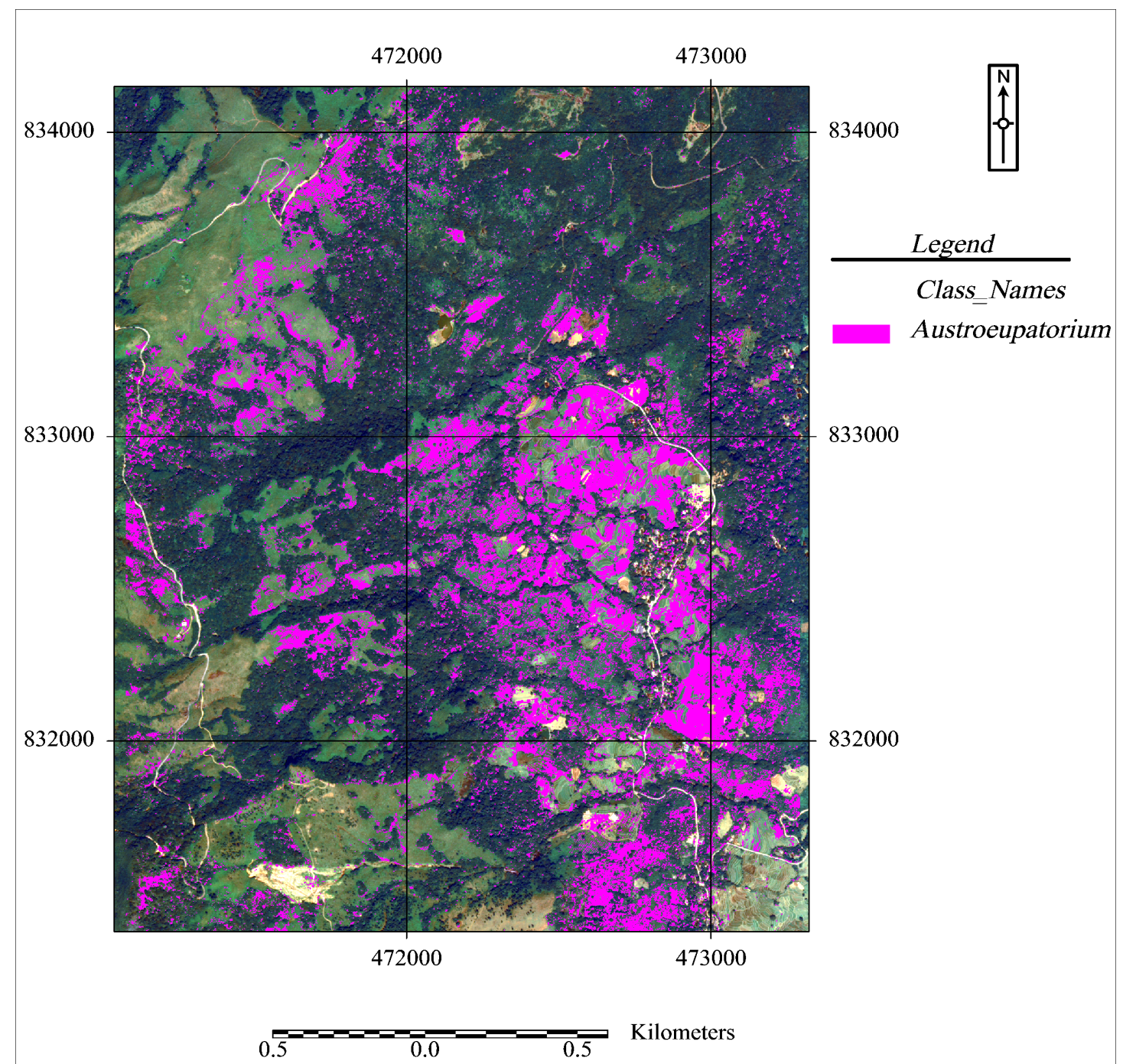

Figure 5: The distribution map of Austroeupatorium inulifolium using knowledge-based classification. In the map, A. inulifolium invaded areas are denoted in dark pink colour.

best methods in detecting and monitoring of invasive plants need to be identified using further research (Müllerováa et al., 2017). With the continuous advancement of satellite imagery and RS technologies besides increasing availability of open access information and open source software, use of RS for mapping invasive plant species will become an essential and readily available tool.

\section{CONCLUSIONS}

The study concludes that the distribution of $A$. inulifolium vary from 15 to $18 \%$ of the selected study in KFR, indicating that the high resolution WorldView-2 imagery could provide an excellent source to map the distribution of invasive shrub species with a high accuracy.

\section{REFERENCES}

Alvarez-taboada, F., Paredes, C., Julián-Pelaz, J. (2017). Mapping of the Invasive Species Hakea sericea using Unmanned Aerial Vehicle (UAV) and WorldView-2 Imagery and an Object-Oriented Approach. Remote Sensing 9, 1-17.

Amiri, M. and Hosseini, S. (2012). Band combinations application for discrimination of Cirsium arvense and Stachys byzanthina Distribution. International journal of Agronomy and Plant Production 3: 437-442.

Becker, R.H., Zmijewski, K.A. and Crail, T. (2013). Seeing the forest for the invasives: Mapping buckthorn in the Oak Openings. Biological Invasions 15: 315-326.

Chen, Q., Laurin, G.V., Battles, J.J. and Saah, D. (2012). Integration of airborne Lidar and vegetation types derived from aerial photography for mapping aboveground live biomass. Remote Sensing of Environment 121: 108-117.

Delalieux, S., Somers, B., Haest, B., Spanhove, T., Borre, J.V. and Mücher, C.A. (2012). Heathland conservation status mapping through integration of hyperspectral mixture analysis and decision tree classifiers. Remote sensing of environment 126: 222-231.

Dlamini, W.M. (2011). Multispectral detection of invasive alien plants from very high resolution 8-band satellite imagery using probabilistic graphical models. Digital Globe 8: 1-17.

Frazier, A.E. and Wang, L. (2011). Remote Sensing of Environment characterizing spatial patterns of invasive species using sub-pixel classifications. Remote Sensing of Environment 115: 1997-2007. 
Frick, A., Weyer, G., Kenneweg, H. and Kleinschmit, B (2005). A knowledge-based approach to vegetation monitoring with Quickbird imagery. In Proceedings of the ISPRS Workshop 2005: High-Resolution Earth Imaging for Geospatial Information.

Gil, A., Lobo, A., Abadi, M., et al. (2013). Mapping invasive woody plants in Azores Protected Areas by using very high-resolution multispectral imagery. European Journal of Remote Sensing 46: 289-304.

Graham, A. [ERDAS tutorial: UAV Weed Classification Workflow]. (2016). Unmanned Aerial Vehicle (UAV) multispectral imagery: Extracting weeds from barley crops. Lakehead University, Canada. Retrieved from https://www.youtube.com/watch? v=wBBECO5XH1k.

Haltuch, M.A., Berkman, P.A. and Garton, D.W. (2000). Geographic Information System (GIS) analysis of ecosystem invasion: Exotic mussels in Lake Erie. Limnology and Oceanography 45(8): 1778-1787.

Huang, C. and Asner, G.P. (2009). Applications of Remote Sensing to Alien Invasive Plant Studies. Sensors 9: 4869-4889.

Immitzer, M., Stepper, C., Böck, S., et al. (2016). Use of WorldView-2 stereo imagery and National Forest Inventory data for wall-to-wall mapping of growing stock. Forest Ecology and Management 359: 232-246.

Jones, D., Pike, S., Thomas, M. and Murphy, D. (2011). Object-based image analysis for detection of Japanese knotweed s.l. taxa (Polygonaceae) in Wales (UK). Remote Sensing 3, 319-342.

Lin, Y., West, G., Belton, D. and Helmholz, P. (2015). MLS-assisted validation of WorldView-2 panchromatic image for estimating Pinus sylvestris crown height. Remote sensing Letters 6(2): 125-134.

Long, W. (2014). Distribution and Drivers of a Widespread, Invasive Wetland Grass, Phragmites australis, in Great Salt Lake Wetlands. M.Sc. Thesis. Utah State University, Utah.

McCormick, C.M. (1999). Mapping exotic vegetation in the Everglades from large-scale aerial photographs. Photogrammetric Engineering \& Remote Sensing 65: 179-184.

Müllerováa, J., Pergl, J. and Sek, P.P. (2013). Remote sensing as a tool for monitoring plant invasions: Testing the effects of data resolution and image classification approach on the detection of a model plant species Heracleum antegazzianum (giant hogweed). International Journal of Applied Earth Observation and Geoinformation 25: 55-65.

Peerbhay, K.Y., Mutanga, O. and Ismail, R. (2015). Random Forests Unsupervised Classification: The Detection and Mapping of Solanum mauritianum Infestations in Plantation Forestry Using Hyperspectral Data. IEEE Journal of Selected Topics in Applied Earth Observations and Remote Sensing 8(6): 3107-3122.

Repaka, R.S., Truax, D., Kolstad, E. and Hara, C. (2004). Comparing spectral and object based approaches for classification and transportation feature extraction from high resolution multispectral imagery. In Proceedings of the ASPRS Annual Conference, 23-28 May, Denver, Colorado, 204-215.

Robinson, T.P., Wardell-Johnson, G.W., Pracilio, G., et al.
(2016). Testing the discrimination and detection limits of WorldView-2 imagery on a challenging invasive plant target. International Journal of Applied Earth Observation and Geo-information 44: 23-30.

Rocchini, D., Andreo, V., Ponti, L., et al. (2015). Potential of remote sensing to predict species invasions: A modeling perspective. Computers and Geosciences 50: 128-135.

Sankey, J.B., Ravi, S., Wallace, C.S.A., Webb, R.H. and Huxman, T.E. (2012). Quantifying soil surface change in degraded dry lands: Shrub encroachment and effects of fire and vegetation removal in a desert grassland. Journal of Geophysical Research: Biogeosciences 117: $1-11$.

Sankey, T., Dickson, B., Sesnie, S., Wang, O., Olsson, A. and Zachmann, L. (2014). WorldView-2 High Spatial Resolution Improves Desert Invasive Plant Detection. Photogrammetric Engineering and Remote Sensing 80(9): 885-893.

Shouse, M., Liang, L. and Fei, S. (2013). Identification of understory invasive exotic plants with remote sensing in urban forests. International Journal of Applied Earth Observation and Geoinformation 21: 525-534.

Somodi, I., Carni, A., Ribeiro, D. and Podobnikar, T. (2012). Recognition of the invasive species Robinia pseudoacacia from combined remote sensing and GIS sources. Biological Conservation 150: 59-67.

Stow, D., Hope, A., Richardson, D., Chen, D., Garrison, C. and Service, D. (2000). Potential of colour-infrared digital camera imagery for inventory and mapping of alien plant invasions in South African shrublands. International Journal of Remote Sensing 21(15): 29652970.

Turner, W., Spector, S., Gardiner, N., Fladeland, M., Sterling, E. and Steininger, M. (2003). Remote sensing for biodiversity science and conservation. Trends in Ecology and Evolution 18: 306-314.

Underwood, E.C., Mulitsch, M.J., Greenberg, J.A., Whiting, M.L., Ustin, S.L. and Kefauver, S.C. (2006). Mapping invasive aquatic vegetation in the SacramentoSan Joaquin Delta using hyperspectral imagery. Environmental Monitoring and Assessment 121: 47-64.

Underwood, E.C., Ustin, S.L. and Ramirez, C.M. (2007). A comparison of spatial and spectral image resolution for mapping invasive plants in coastal California. Environmental Management 39(1): 63-83.

Ustin, S.L., Pietro, D., Olmstead, K., Underwood, E. and Scheer, G.J. (2002). Hyperspectral remote sensing for invasive species detection and mapping. Proceedings of $24^{\text {th }}$ IEEE International Geoscience and Remote Sensing Symposium, Canada pp.1658-1660.

$\mathrm{Xu}, \mathrm{X}$. (2014). A knowledge-based approach of satellite image classification for urban wetland detection. Ph.D. Thesis. City University of New York, USA.

Yu, Q., Gong, P., Clinton, N., Biging G., Kelly, M. and Schirokauer, D. (2006). Object-based detailed vegetation classification with airborne high spatial resolution remote sensing imagery. Photogrammetric Engineering and Remote Sensing 72(7): 799-811. 